\title{
Analisis Pengaruh Dimensi Budaya Organisasi dan Iklim Organisasi terhadap Kinerja Pegawai pada Satuan Polisi Pamong Praja Kota Pontianak
}

\author{
INDAH ASTUTI \\ YUSMAINIAR, SE, MM \\ Sekolah Tinggi Ilmu Ekonomi Boedi Utomo \\ Jl. Ampera No.GG 1-2, Pontianak \\ Email : yusiikoto@gmail.com
}

\section{Diterima 13Agustus 2019; disetujui 6 September 2019}

\begin{abstract}
The company's ability to adapt and change in memanajemeni is one of the company's actions in winning the competition. One of the keys to success in the management of such changes is the existence of organizational culture and organizational climate. Police units of teachers 'Praja Pontianak town is one of the Government organizations that helped organise the governance and development in the city of Pontianak. For it was then the Police Unit of teachers 'Praja Pontianak town should pay attention to how management practices through the application of organizational culture and organizational climate are internal in order to build a good performance for each employee. Therefore it is necessary to do an analysis of organizational culture and organizational climate on performance on a unit of Police teachers 'Praja Pontianak town. Problems in the study is how the influence of the dimensions of organizational culture and organizational climate on performance clerk Police teachers 'Praja Pontianak town? Samples done by stratified random sampling. Of the total population of 110 people taken $30 \%$ or as much as 34 people taken into the sample. Analysis for discussion of using Multiple Regression. Simultaneous test results it can be concluded that the variables of organizational climate and organizational culture has a real influence on performance of respondents on a unit of Police teachers 'Praja Pontianak town. From the analysis of partially can be concluded that the organizational culture and organizational climate has a real influence on performance of respondents on a unit of Police teachers 'Praja Pontianak town.
\end{abstract}

Keywords: Organizational Culture Organizational Climate and Performance

\section{PENDAHULUAN}

Kemampuan organisasi dalam beradaptasi dan memanajemeni perubahan merupakan salah satu tindakan perusahaan dalam memenangkan persaingan. Salah satu kunci sukses dalam manajemen perubahan tersebut adalah adanya budaya organisasi dan iklim organisasi yang baik. Berkaitan dengan pernyataan tersebut maka kesiapan untuk memasuki era globalisasi dimasa mendatang yang penuh dengan tantangan dan perubahan lingkungan yang sangat cepat baik internal maupun eksternal, maka pemerintah di Kalimantan Barat dituntut untuk berkerja lebih profesional dan berperformansi tinggi sehingga mendapatkan hasil kerja yang signifikan.

Satuan Polisi Pamong Praja Kota Pontianak merupakan salah satu organisasi pemerintah yang 
membantu menyelenggarakan pemerintahan dan pembangunan di Kota Pontianak. Satuan Polisi Pamong Praja Kota Pontianak telah banyak berperan menjaga peraturan daerah dalam implementasinya di masyarakat, misalnya penertiban bangunan liar, penertiban gelandangan dan pengemis, bersama aparat kepolisian merazia hotel, tempat hiburan, dan kost-kostan yang diduga dijadikan ajang mesum dan penyalahgunaan narkoba, dan lain sebagainya. Maka untuk menjamin terlaksananya seluruh tugas-tugas sesuai dengan apa yang telah direncanakan oleh organisasi tersebut diperlukan produktivitas kerja pegawai yang tinggi dengan memberikan motivasi kerja kepada para pegawai secara profesional. Satuan Polisi Pamong Praja Kota Pontianak memperhatikan bagaimana praktek manajemen melalui penerapan budaya organisasi dan iklim organisasi secara intern agar dapat membangun kinerja yang baik bagi setiap karyawannya. Hal ini didasari pada kenyataan bahwa apabila praktek manajemen yang berupa budaya organisasi dan iklim organisasi berjalan dengan baik maka akan berdampak pada peningkatan kinerja karyawan. Jadi Satuan Polisi Pamong Praja Kota Pontianak harus mampu menciptakan budaya organisasi dan iklim organisasi yang dapat menunjang kinerja karyawannya.

Adapun tujuan dari penelitian ini adalah untuk mengetahui pengaruh budaya organisasi dan iklim organisasi terhadap kinerja karyawan Satuan Polisi Pamong Praja Kota Pontianak.

\section{LANDASAN TEORI}

Robbins (2006) menjelaskan bahwa budaya organisasi adalah kepribadian atau perasaan organisasi. Budaya organisasi mempengaruhi cara manusia bertindak di dalam organisasi (seperti bagaimana bekerja, bekerjasama dengan rekan sekerja dan lain-lain) yang sebagian besar ditentukan oleh norma budaya, nilai-nilai dan kepercayaan yang merupakan komponen budaya. Davis (2001) budaya organisasi adalah totalitas pola perilaku dan karakteristik pola pemikiran dari karyawan suatu organisasi, keyakinan, pelayanan, perilaku dan tindakan karyawan. Litwin (2002) mendefinisikan iklim organisasi sebagai suatu set dari sifat-sifat yang dapat diukur dari suatu ling- kungan organisasi yang didasarkan pada suatu persepsi secara kolektif dari orang-orang yang hidup dan bekerja.

Seymour (2001) mengemukakan bahwa kinerja merupakan tindakan-tindakan atau pelaksanaan tugas yang dapat diukur. Bernandin dan Russel (2003), bahwa kinerja merupakan catatan perolehan yang dihasilkan dari fungsi suatu pekerjaan tertentu atau kegiatan selama periode waktu tertentu. Prawirosentono (2002) kinerja merupakan hasil kerja yang dicapai oleh seseorang atau sekelompok dalam suatu organisasi dalam kurun waktu tertentu, sesuai dengan wewenang dan tanggung jawab masing-masing, dalam rangka upaya mencapai tujuan organisasi yang bersangkutan secara legal, tidak melanggar hukum dan sesuai dengan moral maupun etika.

Penelitian Terdahulu. Simanjuntak (2016), pengaruh budaya organisasi dan disiplin kerja terhadap kinerja karyawan PT. Kereta Api Indonesia (PERSERO) DAOP IV Semarang, hasil penelitian ini menunjukkan variabel budaya organisasi dan disiplin kerja ada pengaruh positif dan signifikan terhadap kinerja pegawai Pt. Kereta Api Indonesia (DAOP Semarang).

Putri Nur Rizky (2014), pengaruh pengawasan, lingkungan kerja dan kompensasi terhadap kinerja pada guru sertifikasi, hasil penelitian menunjukkan variabel pengawasan, lingkungan kerja dan kompensasi ada pengaruh terhadap kinerja pada guru sertifikasi.

\section{Hipotesis}

H1 : Terdapat pengaruh dimensi budaya organisasi dan iklim organisasi terhadap kinerja Pegawai Pada Satuan Polisi Pamong Praja Kota Pontianak.

H2 : Terdapat pengaruh iklim organisasi terhadap kinerja Pegawai Pada Satuan Polisi Pamong Praja Kota Pontianak.

H3 : Terdapat pengaruh budaya organisasi dan iklim organisasi terhadap kinerja Pegawai Pada Satuan Polisi Pamong Praja Kota Pontianak.

\section{METODE PENELITIAN}

Jenis pendekatan penelitian ini adalah deskriptif yakni penelitian yang berusaha mendeskripsikan 
suatu gejala, peristiwa, kejadian yang terjadi saat sekarang pada Satuan Polisi Pamong Praja Kota Pontianak. Populasi dalam penelitian ini adalah semua karywan Satuan Polisi Pamong Praja Kota Pontianak sebanyak 110 (seratus sepuluh) orang dan sampel ditetapkan sebesar 30\% dari jumlah populasi yang ada atau sebanyak 34 orang pegawai berdasarkan tingkat pendidikan. Variabel bebas dalam penelitian ini yaitu budaya organisasi (X1) dan iklim organisasi (X2), sedangkan variabel terikat yaitu kinerja (Y). Teknik pengumpulan data di penelitian ini menggunakan kuesioner yang di sebarkan.

Adapun definisi operasional variabel di penelitian ini :

1. Variabel Bebas

a. Budaya Organisasi (X1)

Robbins (2006), menjelaskan bahwa budaya organisasi adalah kepribadian atau perasaan organisasi. Sub variabelnya meliputi senyum, menyapa, akurat, respon dan tertib. Pengukuranya menggunakan skala ordinal.

b. Iklim Organisasi (X2)

Litwin (2002) mendefinisikan iklim organisasi sebagai suatu set dari sifat-sifat yang dapat diukur dari suatu lingkungan organisasi yang didasarkan pada suatu persepsi secara kolektif dari orang-orang yang hidup dan bekerja. Sub variabelnya meliputi konformitas, standar, imbalan, kerja kelompok, kejelasan organisasi dan tanggung jawab. Pengukuranya menggunakan skala ordinal.

\section{Variabel terikat: Kinerja (Y)}

Seymour (2001) mengemukakan bahwa kinerja merupakan tindakan-tindakan atau pelaksanaan tugas yang dapat diukur. Sub variabelnya meliputi kemampuan, motivasi dan kesempatan. Pengukuranya menggunakan skala ordinal.

Metode analisis data penelitian ini menggunakan analisis Regresi Linier Berganda.

\section{HASIL PENELITIAN}

Dari 34 responden di penelitian ini, jumlah responden terbesar adalah responden yang berumur antara 34 - 40 sebanyak 21 orang dan jumlah responden terkecil berada pada kelompok umur antara 55 - 61 tahun sebanyak 2 orang, sedangkan sisanya dari kelompok umur yang secara ekonomis tidak produktif ialah kelompok umur 65 tahun keatas. Jenis kelamin responden adalah sebanyak 26 orang responden adalah laki-laki dan sebanyak 8 orang responden perempuan. Dari data yang terkumpul diketahui bahwa responden terbesar berpendidikan SLTA/SMA sebanyak 29 orang, sedangkan yang terkecil berpendidikan SD, SMP, D-3, S1 dan S2 yang masing-masing berjumlah 1 orang.

Dari hasil analisis data menunjukkan bahwa besarnya pengaruh dari budaya organisasi dan iklim organisasi terhadap naik turunnya atau variasi variabel kinerja adalah sebesar 55,10\% sedangkan sebesar 44,90\% dipengaruhi oleh variabel lain selain variabel dalam penelitian ini. Kesimpulan ini diperoleh dari nilai Koefisien Determinasi (R2) yaitu sebesar 0,551.

Uji Validitas dan Reliabilitas. Dari hasil uji validitas, semua item pertanyaan memiliki nilai korelasi positif dan lebih besar dari 0,6. Hal ini berarti bahwa semua instrumen dalam penelitian ini adalah valid. Begitu pula, hasil uji reliabilitas menunjukkan semua variabel memiliki nilai koefisien Alpha Chronbach lebih besar dari 0,6, yang artinya bahwa seluruh instrumen yang digunakan dalam penelitian ini adalah reliabel.

Uji Asumsi Klasik. Sebelum dilakukan uji regresi linear berganda maka dilakukan uji asumsi klasik, dari hasil uji multikolerianitas menunjukkan bahwa tidak ada nilai VIF yang lebih dari 10 sehingga dapat dikatakan bahwa tidak ada korelasi antara variabel bebas. Selanjutnya nilai signifikansi tiap variabel terhadap absolute residual lebih dari 0,05 , artinya persamaan regresi mengalami homokedastisitas (tidak mengandung Heterokedastisitas) dan untuk uji normalitas data penelitian ini berdistribusi normal, dikarenakan nilai $\alpha$ lebih besar dari 0,05.

Analisis Regresi Berganda. Analisis regresi berganda dilakukan meliputi variabel bebas dimensi budaya organisasi $\left(\mathrm{X}_{1}\right)$ dan dimensi iklim organisasi $\left(\mathrm{X}_{2}\right)$ terhadap variabel terikat kinerja $(\mathrm{Y})$.

Dari hasil analisis pada Tabel 1 tersebut diketahui secara simultan nilai $\mathrm{F}$ hitung sebesar 19,005 pada tingkat signifikan 0.000 dan karena tingkat probabilitasnya 0.000 jauh lebih kecil dari 
0.05 maka model regresi ini dapat digunakan untuk memprediksi hubungan antara variabel independent terhadap variabel dependent. Nilai F tabel 0.05 diperoleh dengan memperhatikan besarnya nilai degree of freedom (df) atau $(\mathrm{k}-1)$ dan $(n-3)$, dimana $k$ adalah jumlah variabel dan $n$ adalah jumlah sampel. Nilai $F$ tabel 0.05 adalah sebesar 3,30, sedangkan nilai $\mathrm{F}$ hitung sebesar 19,005. Jadi nilai $F$ hitung > nilai $F$ tabel, yaitu $19,005>3,30$, sehingga dapat disimpulkan bahwa antara variabel budaya organisasi dan iklim organisasi mempunyai pengaruh yang nyata terhadap kinerja responden pada Satuan Polisi Pamong Praja Kota Pontianak.

Adapun hasil uji secara parsial pengaruh budaya organisasi dan iklim organisasi terhadap kinerja responden pada Satuan Polisi Pamong Praja Kota Pontianak pada Tabel 2 dapat di lihat secara parsial variabel budaya organisai memiliki nilai t hitung sebesar 4,308 dimana lebih besar darit tabel $\alpha 0.05$, yaitu 4,308 > 1,695. Maka dapat disimpulkan bahwa pada penelitian ini variabel budaya organisasi secara parsial mempunyai pengaruh yang nyata terhadap kinerja responden pada Satuan Polisi Pamong Praja Kota Pontianak. Secara parsial variabel iklim organisasi memiliki nilai $\mathrm{t}$ hitung sebesar 4,463 dimana lebih besar dari t tabel $\alpha 0.05$, yaitu 4,463>1,695. Maka dapat disimpulkan bahwa pada penelitian ini variabel iklim organisasi secara parsial mempunyai pengaruh yang nyata terhadap kinerja responden pada Satuan Polisi Pamong Praja Kota Pontianak.

Adapun hasil uji secara parsial pengaruh budaya organisasi dan iklim organisasi terhadap kinerja responden pada Satuan Polisi Pamong Praja Kota Pontianak pada Tabel 2 dapat di lihat secara parsial variabel budaya organisai memiliki nilai t hitung sebesar 4,308 dimana lebih besar dari t tabel $\alpha 0.05$, yaitu 4,308 > 1,695. Maka dapat disimpulkan bahwa pada penelitian ini variabel budaya organisasi secara parsial mempunyai pengaruh yang nyata terhadap kinerja responden pada Satuan Polisi Pamong Praja Kota Pontianak. Secara parsial variabeliklim organisasi memiliki nilai $\mathrm{t}$ hitung sebesar 4,463 dimana lebih besar dari t tabel $\alpha 0.05$, yaitu 4,463>1,695. Maka dapat disimpulkan bahwa pada penelitian ini variabel iklim organisasi secara parsial mempunyai pengaruh yang

Tabel 1

Analisis Of Variance Budaya Organisasi dan Iklim Organisasi Terhadap Kinerja

\begin{tabular}{llllll}
\hline Model & $\begin{array}{l}\text { Sum Of } \\
\text { Square }\end{array}$ & df & $\begin{array}{l}\text { Mean } \\
\text { Square }\end{array}$ & F & Sig. \\
\hline Regression & 47,239 & 2 & $\begin{array}{l}23,619 \\
1,243\end{array}$ & 19,005 & $.000^{\mathrm{a}}$ \\
Residual & 38,526 & 31 & & & \\
\hline Total & 85,765 & 33 & & & \\
\hline
\end{tabular}

Sumber : Analisis Data, 2017

Tabel 2

Analisis Uji t, Budaya Organisasi dan Iklim Terhadap Kinerja

Coefficients

\begin{tabular}{llrrrrr}
\hline \multirow{2}{*}{ Model } & \multicolumn{2}{c}{ Unstandardized } & \multicolumn{2}{c}{$\begin{array}{c}\text { Standardized } \\
\text { Coefficients }\end{array}$} & t & Sig. \\
\cline { 3 - 5 } & \multicolumn{2}{c}{ Coefficients } & \multicolumn{2}{c}{ Beta } & \\
\hline \multirow{2}{*}{1} & (Constant) & 28,865 & 2,843 & & 10,152 & 0,000 \\
& Budaya Organisasi & 0,467 & 0,108 & 0,519 & 4,308 & 0,000 \\
& Iklim Organisasi & 0,398 & 0,089 & 0,537 & 4,463 & 0,000 \\
\hline
\end{tabular}

Dependent Variable: KINERJA Sumber : Analisis Data, 2017 
nyata terhadap kinerja responden pada Satuan Polisi Pamong Praja Kota Pontianak.

\section{PEMBAHASAN}

Budaya organisasi sangat berpengaruh terhadap kinerja karena dengan senyum, menyapa, memberikan informasi yang akurat, dan memberikan respon yang positif akan terbangun suatu awal bentuk komunikasi yang baik antara responden dan masyarakat, sehingga pada akhirnya akan berimplikasi pada kegairahan bekerja dan kinerja akan menjadi semakin lebih dapat ditingkatkan. Pada sebuah instansi yang memiliki budaya organisasi yang baik maka dapat membantu kinerja pegawainya. Dengan budaya organisasi yang baik maka akan meningkatkan motivasi pegawainya dalam memberikan kemampuannya yang luar biasa. Untuk menerapkan suatu budaya organisasi yang cocok pada sebuah instansi, diperlukan adanya dukungan dan partisipasi dari semua pegawai yang ada dalam lingkup instansi tersebut.

Iklim organisasi sangat berpengaruh terhadap kinerja karena iklim organisasi yang ada pada Satuan Polisi Pamong Praja Kota Pontianak yang terdiri dari konformitas, standar, imbalan, kerja kelompok, kejelasan organisasi dan tanggung jawab merupakan suatu wahana yang sudah dikelola dan dimiliki serta telah disediakan oleh manajemen Satuan Polisi Pamong Praja Kota Pontianak untuk menunjang kelancaran bekerja segenap pegawainya, sehingga apa yang menjadi beban kerja setiap pegawai dapat diselesaikan dengan baik. Iklim organisasi Satuan Polisi Pamong Praja Kota Pontianak mempengaruhi kondisi dasar dan perilaku pegawai, dan pemimpin merupakan salah satu faktor paling dominan yang paling mempengaruhi bentuk dari iklim organisasi, sehingga berdampak terhadap faktor-faktor yang mempengaruhi pencapaian tujuan instansi. Iklim organisi ini yang akhirnya akan mempengaruhi kinerja pegawai.

Hal ini didukung oleh keadaan bahwa para responden yang menyatakan pada kondisi sekarang kinerja responden yang ada cukup menunjang terciptanya kesetiaan pegawai terhadap organisasi yang tentunya ditunjang oleh budaya organisasi dan iklim organisasi yang memadai dan praktek manajemen yang lebih proporsional. Kondisi tersebut sesuai dengan tujuan utama setiap organisasi menetapkan budaya organisasi dan iklim organisasi adalah untuk memotivasi pegawai dalam rangka meningkatkan kinerjanya serta mempertahankan pegawai yang kompeten. Budaya organisasi dan iklim organisasi yang baik tentunya akan memiliki dampak yang positif pada Satuan Polisi Pamong Praja Kota Pontianak. Di satu sisi, selain akan mempengaruhi perilaku dan sikap kerja pegawainya, budaya orgasnisasi dan iklim organisasi juga akan memberikan karakter yang kuat pada setiap pegawai Satuan Polisi Pamong Praja Kota Pontianak.

\section{SIMPULAN}

Kesimpulan. Berdasarkan hasil analisis penelitian sebagaimana yang telah diuraikan, berikut ini disampaikan beberapa kesimpulan sebagai berikut :

1. Dari hasil analisis data menunjukkan bahwa besarnya pengaruh dari budaya organisasi dan iklim organisasi terhadap naik turunnya atau variasi variabel kinerja adalah sebesar 55,10\% sedangkan sebesar 44,90\% dipengaruhi oleh variabel lain selain variabel dalam penelitian.

2. Dari fungsi regresi dapat disimpulkan bahwa variabel budaya organisasi dan iklim organisasi mempunyai pengaruh yang positif terhadap kinerja responden pada Satuan Polisi Pamong Praja Kota Pontianak.

3. Dari hasil uji secara simultan dapat disimpulkan bahwa variabel budaya organisasi dan iklim organisasi mempunyai pengaruh yang nyata terhadap kinerja responden pada Satuan Polisi Pamong Praja Kota Pontianak.

4. Dari hasil analisis secara parsial dapat disimpulkan bahwa budaya organisasi dan iklim organisasi mempunyai pengaruh yang nyata terhadap kinerja responden pada Satuan Polisi Pamong Praja Kota Pontianak.

Saran. Dari kseimpulan tersebut maka penulis menyampaikan rekomendasi berkenaan dengan penelitian ini sebagai berikut :

1. Hendaknya Satuan Polisi Pamong Praja Kota Pontianak dapat mempertahankan budaya organisasi yang cocok bagi instansi dan 
menciptakan iklim organisasi yang baik agar kinerja dapat lebih ditingkatkan.

2. Manajemen Satuan Polisi Pamong Praja Kota Pontianak perlu memberikan reward bagi karyawan yang berkinerja tinggi dan memberikan punishmen bagi karyawan yang kinerjanya jelek.

3. Manajemen Satuan Polisi Pamong Praja Kota Pontianak hendaknya dapat memberdayakan semua sumber daya yang ada khususnya sumber daya manusia (employee empowerment), meningkatkan produktivitas (productivity) berdasarkan analisis jabatan (job analysis) dan beban kerja (job tasks).

\section{DAFTAR PUSTAKA}

Bacal, Robert. 2001. Performance Management. 2002. PT. Gramedia Pustaka Utama. Jakarta

Bernardin, H Hon dan Hoyce, EA. Russel. 2003. Human Resources Management. Mc Graw Hill Inc, Singapore.

Dharma, Agus. 2000. Manajemen Prestasi Kerja, Rajawali Press.

Davis, Kerth and Werther, Newstrom B. 2001. Human Resources and Personnel Management. 5th edition. McGraw-Hill, Inc. USA.

Dessler, Garry. 2006. Manajemen Sumber Daya Manusia. Jilid I. Penrbit PT. Prenhalindo, Jakarta.

Gomes. 2005. People In organizarion : In Intriduction To Organization Behavior. Mc-Graw Hill Book Comp. Tokyo

Gibson James L.; Ivancevich John M dan Donnely James H. Jr. 2005. Organisasi: Perilaku, Struktur, Proses. Jilid I. Alih bahasa: Ir. Nunuk Adiarni, MM, Binarupa Aksara, Jakarta.

Hasibuan, Malayu. SP. 2000. Manajemen Sumber Daya Manusia, Penerbit PT. Toko Gunung Agung, Jakarta.

Heneman, Schab, Fossum. 2001. The Mesurement And Atencedents Of Afective, Continuance And Normative Commitment To The Organization.
Journal Of Occupational Psychology.

Harini, Agustina. 2002. Analisis Hubungan Antara

Komitmen Dengan Iklim Organisasi Dan

Performansi Karyawan Divre II Telkom,

Bandung Journal Riset Ekonomi Dan

Manajemen. Penerbit Ikatan Sarjana Ekonomi

Indonesia (ISEI), Cabang Surabaya.

Hatch. 2001. Organization Culture and Leadership, Jossey-bass Publisher, San Fransisco.

Hersey, Paul and Ken Blanchard. 2008.

Management of Organizational Behavour,

Prentice Hall, new Jersey.

Kotler, Philip Dan Armstrong. 2007. Manajemen Pemasaran, alih bahasa Wilhelmus W

Bakowatun, Jilid 1 Jakarta, CV Intermedia.

Luthans Fred. 2000. Organizational Behaviour, Eleventh Edition, McGraw-Hill, Inc.

Swasto, Bambang. 2006. Manajemen Sumber Daya Manusia, FIA- UNIBRAW, Malang,

Moehardi Daniel. 2001. Metode Penelitian Sosial Ekonomi. Penerbit Bumi Aksra. Jakarta.

Nimran. 2007. Manajemen Personalia Dan Sumber Daya Manusia. BPFE, Yogyakarta.

Prawirosentono, Suyadi. 2002. Manajemen Sumber Daya Manusia (Kebijakan Kinerja Krayawan). BPFE. Yogyakarta.

Prijono, Sutyastie. 2003, Pemberdayaan Penduduk Dan Peningkatan Kualitas Sumber Daya Manusia. PT. Citra Putra Bangsa. Jakarta.

Robbins, Stephen P. dan Mary Coulter. 2006. Manajemen, Soutwest Missouri State University. Penerbit PT. Prenhallindo Jakarta.

Sutojo, Ahmad. 2003. Peran Budaya Organisasi : Sumber Daya Manusia, Jakarta: Gramedia Pustaka Utama.

Suparmoko. Irawan. 2003. Metode Statistik Parametrik. BPFE. Yogyakarta.

Simamora, Henry. 2007. Manajemen Sumber Daya Manusia, Edisi ke satu, Cetakan Pertama, Penerbit Bagian Sekolah Tinggi Ilmu Ekonomi YKPN, Yogyakarta.

Schuler, Randhall, dan Samuel, Jackson. 2007. Manajemen Sumber Daya Manusia, Mengahdapai Abad 21. Edisi 6 Jilid 2. Penrbit Erlangga. Jakarta. 